\title{
ASSESSMENT OF DESIGN SKY FOR DESIGN OF DAY LIGHTING IN BUILDINGS IN CAPITAL REGION DELHI, INDIA.
}

\author{
Prof.Dr.Ramesh Srikonda ${ }^{1}$
}

\begin{abstract}
Window is an opening designed or created in the wall or any exposed surface to external environment to admit daylight and cross ventilation and also contributing to thermal comfort conditions. The primary function of a window/opening is served by a sheet of glass fixed in the frame of the window/ opening, which can be termed as a dead light if no part of the window/opening can be opened. As the window/opening is the part of the wall or roof envelop to the building, it should serve to exclude wind, rain, and act as a barrier to excessive transfer of heat, sound and spread of fire in much the same way of the surrounding wall or roof. The functional material of a window/opening glass is effective enough to admit daylight and excluding wind and rain but is a poor barrier to the transfer of heat, sound and spread of fire. The traditional window/opening is usually designed to ventilate rooms through one or more parts that open to encourage/allow an exchange of air between indoor and outdoor environment. Ventilation is not a necessary function of a window/opening for controlled environment but it is an essential parameter for the non-air conditional buildings in general and tropical countries in particular. This paper deals exclusively to draw adequate daylight to internal spaces from available day light at outside. So it is felt essential to analyze the available day light at outside particularly at Delhi region, India which can be used as design sky to work out the desirable daylight to requirement to indoor functional space. NBC 2005 generalized the available day light for India to size the window/ openings, roof light, north light etc., to even draw desirable lighting levels. But India is a large country having wide variations in natural lighting conditions. So the indoor day lighting varies from location to location with respect to the cloudy days etc. Unless the exact Design sky is not known to a particular station, the opening design may contribute to either under lighting or over lighting to the indoor spaces. The under lighting may force the occupants to use artificial lighting, whereas over lighting may result to admit excessive heat. In addition to this, increased size of the opening may cost more relatively, in comparison to the vertical wall.

Keywords: Indoor lighting, Sky component, Design Sky, Daylight factor.
\end{abstract}

\section{INTRODUCTION}

The primary function of a window/opening is allowing daylight for daytime functional activities in adequate quantity for efficient performance. It is essential to take the maximum advantage of the free source of illumination energy when the artificial lighting illumination is so extravagantly consuming the natural fuel sources and grossly expensive. The accepted minimum level of daylight for the performance of various activities varies from one functional space to another. Recent Studies have emphasized $[2,4,17]$ that the quality of light produced by the sun and sky is a very dynamic and attractive reason for day lighting. As per IES Lighting Handbook of 10h Edition,[11,12] the daylight autonomy appears to be simple, the percentage of sensors to achieve a desirable luminance level of typical 300 lux with regard to operating period and it may also includes spatial daylight autonomy. It also pave a way to understand other dynamic daylight metrics, continuous daylight autonomy, maximum daylight autonomy and useful daylight luminance.[9]. A poor quality of daylight may result in discomfort and a loss in visibility, which may cause a decrease in human performance and productivity. This, in turn, may lead increased use of the space, resulting in additional energy consumption [20]. Reinhart [21] had emphasized the dynamic daylight performance metrics for sustainability in building. The importance day lighting has been emphasized with automated roller shades in an office building [22].

The historical buildings in India were designed with courtyards to bring sunlight into the core of the buildings and overhangs appropriately sized to shade the interior from the summer sun [10]. Even after the advent of the electric light, buildings were still designed to have large amount of perimeter area to provide adequate ventilation and day lighting. Accordingly the desired daylight factors i.e. the percentage of daylight to be admitted through a window/opening from the hemisphere of the unobstructed sky. The amount of light admitted depends on the size of the window/opening or window/openings in relation to the area of the room, the depth of the room to which useful light will penetrate depends on the area of the window/opening and the height of the head of the window/opening above floor level. Daylight intensity varies considerably both hourly and daily due to the rotation of the earth and the consequent relative position of the sun and also due to the climatic variations from clear to overcast skies. In order to make a prediction of relative levels of daylight indoors it is necessary to make accurate calculations of available day light intensity on that area or zone. The concept of day light has the advantage that it is a comparative value of the intensity of daylight indoors at different points so that even though the intensity of day light outdoors will vary but the relative indoor intensity will remain more or less the same. The daylight concept presents better

\footnotetext{
${ }^{1}$ Department of Architecture, School of Planning and Architecture Vijayawada, A. P., India
} 
indication of the subjective impression of daylight than the case where an absolute value is given. However, the intensity of illumination of the standard sky is assumed to be uniform to facilitate calculation of levels of daylight. In general, sky luminance varies, with luminance at the horizon being about one third of that at the sun's zenith. The Perez [19] had developed a model that gives luminance efficacy with respect to zenith angle, sky clearance, sky brightness and atmospheric perceptible water content. Several components involved in indoor lighting analysis even including glare factors as expressed in literature [5]. But, the assessment of the available daylight or design sky is essential so the accuracy of energy analysis depends upon the quantum of day light drew from the design sky.

Successfully admitting renewable natural light into a space reduces the need to supply electric light, which is usually generated at the expense of a non-renewable resource [23-24]. Using daylight can therefore be considered good stewardship of the vast natural wealth. Another reason for promoting day lighting is closely associated with energy conservation. Energy cost savings can accrue because of lower electric lighting consumption. Recent Studies have emphasized,[2] that the quality of light produced by the sun and sky is a very dynamic and attractive reason for day lighting. It changes in intensity every moment on a partly cloudy day. Every day the color, directionality, and intensity vary from morning to midday to evening. Light reflected from the ground depends on the reflective properties of the ground cover. The effectiveness of ground light is also dependent on the orientation (exposure to direct sun) of the window/opening/openings, obstructions between sun and ground and/or ground and window/opening and the height of the window/opening above the ground. It is assumed that the ground plane extends away from the vertical plane of the window/opening up to an infinite distance. This simplifies calculations because the configuration factor between a point on a vertical plane and an infinite horizontal plane is 0.5. A poor quality of daylight may result in discomfort and a loss in visibility, which may cause a decrease in human performance and productivity. This, in turn, may lead increased use of artificial lighting, resulting in additional energy consumption [17].

\section{DESIGN SKY}

\subsection{Daylight Factor}

The daylight intensity at any point inside a room is subject to severe and frequent fluctuations, but it is, however, found to bear a constant ratio for the simultaneous external intensity when the sky is clear or overcast [15]. It is expressed in terms of intensity of day light illumination inside a room at any point in any plane as a ratio or percentage of the simultaneous intensity in a horizontal plane at an outside point open to the entire sky vault. Direct sunlight, if any, is not considered for both interior and exterior values of illumination. This effect can be accommodated by considering the daylight levels in indoor spaces with respect to the light from the sky. This may be quantified in the daylight factor, which is defined as:

illumminance in room $100 \%$

$\mathrm{DF}=$ horizontal $\square$ lilluminance $\square$ from $\square$ an $\square$ unobstructed $\square$ diffuse $\square$ sky

Recommended lighting luminance values for different functional activities were tabulated by the Bureau of Indian Standards [3], Illuminating Engineering society of North America (IES), as well as by, the Commission International de I' Éclair age (CIE).

Further, the light factor is a measure of all the daylight reaching on an indoor reference point from the direct sky, external surfaces reflecting light directly to the point, and internal surfaces reflecting and inter-reflecting light to the point. Each of three components, when expressed as a ratio or percent of the simultaneous external illumination on the horizontal plane define respectively the sky component (SC), the external reflected component (ERC) and the Internal reflected component (IRC). The daylight factor on horizontal plane only usually taken as the working plane in a room is generally horizontal; however the factors in the vertical planes should also be considered when specifying day lighting values for special cases, such as daylight on a class room blackboard, wall hanger pictures or paintings in exhibition halls.

$\mathrm{DF}=(\mathrm{SC}+\mathrm{IRC}+\mathrm{ERC})$

Illumination $=\square \mathrm{MF}$. GBC .(SC+IRC+ERC) X [(Design sky)/100]

where

$\square=$ Transmittance of the glazing

$\mathrm{MF}=$ Maintenance factor for conditions

GBC = Glazing bar correction

The daylight factor is to be calculated at a number of points on a regular grid with in the room, a series of contours can be drawn which connects together those points which have the same daylight factor/intensity. Such daylight contours show how the daylight varies within the room. The quantitative analysis of daylight is developed in order to investigate the daylight intensity level at different grid point, and further contours of the daylight developed to show the qualitatively distribution pattern of light. Fig.5 shows the grid points in relation to $\mathrm{x}$ and $\mathrm{y}$-axis of working plane and the position of the window/opening. The same pattern can be seen in the tables as well as in the figures. 


\subsection{Sky component}

Sky component is the ratio of that part of the daylight illumination at a point on given plane, which is received directly from the sky as compared to the simultaneous exterior illumination on a horizontal plane from the entire hemisphere of an unobstructed clear design sky. The values are corrected by considering the window/opening bars, glazing and external obstructions. The correction for window/opening bars is carried by multiplying the values by a factor equal to the ratio of the clear opening to the overall opening [7]. Where window/openings are glazed, the arrived sky component is reduced by about 10 to $20 \%$ provided the panes are of clear glass

\subsection{Internal and External Reflected Component}

The component of day light factor contributed by reflection from the inside surfaces varies directly as the window/opening area and inversely as the total area of internal surfaces, and depends on the reflection factors of the floor, wall and roof surfaces insides and of the ground outside. For rooms white washed on walls and ceiling and window/openings of normal sizes, the IRC will have a sizeable value even at points far away from the window/opening. External obstructions, when present, will proportionally reduce the IRC. For accurate values of IRC, a precise method of evaluation of the same is given below. The values of the sky component corresponding to the portion of the window/opening obstructed by the external obstruction are to be considered to achieve the ERC. The average IRC can be determined from the NBC 2005 inter-reflection formula. The simplified form of this is:

$\mathrm{IRC}_{\mathrm{avr}} \square 0.85 \mathrm{~A}_{\mathrm{w}}\left(\mathrm{C}^{\square} \mathrm{fw} \square 10 \square_{\mathrm{cw}}\right)$

$\mathrm{A}_{\mathrm{T}}(1 \square \mathrm{R})$

where, $0.85=$ Transmittance value of window/opening glazing $\mathrm{A}_{\mathrm{w}}=$

window/opening area

$\mathrm{A}_{\mathrm{T}}=$ total surface area (ceiling +floor +walls including window/openings)

$\square_{\mathrm{fw}}=$ Average reflection of floor and the three walls below the plane at level mid height of the window/opening (excluding the window/opening wall) $\mathrm{cw}=$ Average reflectance of the ceiling and the upper part of the above three walls.

$\underline{\mathrm{C}}=\mathrm{A}$ constant of value 78 when there is no external obstruction [2]

$\underline{\mathrm{R}}=$ The average reflection factor of all surfaces in the room (ceiling, wall and window/openings).

So as to workout exact illumination level with reference to the window sizing, it is essential and crucial to know the design sky as elaborated above. So the focus of the paper is to work out the exact design sky of Andhra Pradesh region, India. Hence it has been proposed to study and analyze the IES model and practical conditions to work out the exact, diffused, direct, global daylight intensity with regard to clear sky, part cloudy and over cast sky $[13,14]$. This detailed investigation has been validated with respect to the actual measurements taken on $15^{\text {th }}$ June and $15^{\text {th }}$ January 2017.

\section{IES DAYLIGHT MODEL}

The mean extraterrestrial illuminance, $\mathrm{E}_{\mathrm{sc}}$, obtained from ASTM standard spectral irradiance data set i.e., $\mathrm{E}_{\mathrm{sc}},=127.5 \mathrm{klux}$. The extraterrestrial illumination varies with reference to Julian day, ' $n$ ' by the following expression.

$\mathrm{E}_{\mathrm{o}}=\mathrm{E}_{\mathrm{sc}}[1+0.033 \cos (360 \mathrm{n} / 365)]$

Similar to the calculation of direct beam irradiance, direct beam illuminance, $\mathrm{E}_{\mathrm{DN}}$, has the following form [8,9] [IES

(1984), Gillette et al (1984))]

$\mathrm{E}_{\mathrm{DN}}=\mathrm{E}_{0} \mathrm{e}^{-\mathrm{am}}$

Where,

$\mathrm{a}=$ extinction coefficient, their values are given in table-1 for varying sky conditions.

$\mathrm{m}=$ air mass

The horizontal diffuse sky illumination, $\mathrm{E}_{\mathrm{d}}$ has been given in the following form by many authors with differing coefficients. The coefficients agreed with by the IES calculation procedure as given below in Table 1a [16]

$\mathrm{E}_{\mathrm{d}}=\mathrm{A}+\mathrm{B}[\cos (\mathrm{Z})]^{\mathrm{C}}$

$\mathrm{A}=$ sunrise/sun set illuminance coefficient, klux

$\mathrm{B}=$ solar altitude illuminance coefficient, klux

$C^{\prime}=$ solar altitude illuminance exponent

$\mathrm{Z}=$ zenith angle

Table 1 IES daylight constants

\begin{tabular}{|l|l|l|l|l|l|}
\hline $\begin{array}{l}\text { Sky ratio } \\
\text { Idiff / IT }\end{array}$ & Sky condition & Ext. Coefficient (a) & $\begin{array}{l}\text { A } \\
\text { klux }\end{array}$ & $\begin{array}{l}\text { B } \\
\text { klux }\end{array}$ & $\begin{array}{l}\text { C } \\
\text { klux }\end{array}$ \\
\hline$<0.28$ & Clear & 0.21 & 0.8 & 15.5 & 0.5 \\
\hline $0.28-0.8$ & Partly Cloudy & 0.8 & 0.3 & 45.0 & 1.0 \\
\hline$>0.8$ & Overcast & - & 0.3 & 21.0 & 1.0 \\
\hline
\end{tabular}

Using this simple model direct and diffuse illuminance has been derived for Delhi conditions. 


\section{RESULTS AND DISCUSSION}

\subsection{IES method of outdoor illumination levels for design daylight}

The mean extra-terrestrial illuminance, $\mathrm{E}_{\mathrm{sc}}$, is obtained by the ASTM standard irradiance data set. This yields a mean extraterrestrial luminance of 127.5 klux and with similar calculations of direct beam irradiance [1], the direct and horizontal diffuse sky luminance are computed with respect to the IES calculation procedure for $15^{\text {th }}$ June and $15^{\text {th }}$ January for Delhi meteorological conditions as with above mentioned parameters. Besides, the IES daylight availability constants as shown in the table: 1 incorporated for different sky conditions i.e., clear sky (CS), partly cloudy (PC), \& overcast sky (OC) to arrive diffuse and direct illumination levels for design sky light which is basic requirement to arrive the daylight factor on the working plane.

Figs. 1, $2 \& 3$ show the computed available day light intensity of for the month of January for global, diffuse and beam illumination levels for different sky conditions. Similarly that the Figs: 4, $5 \& 6$ show the available daylight intensity for $15^{\text {th }}$ June.

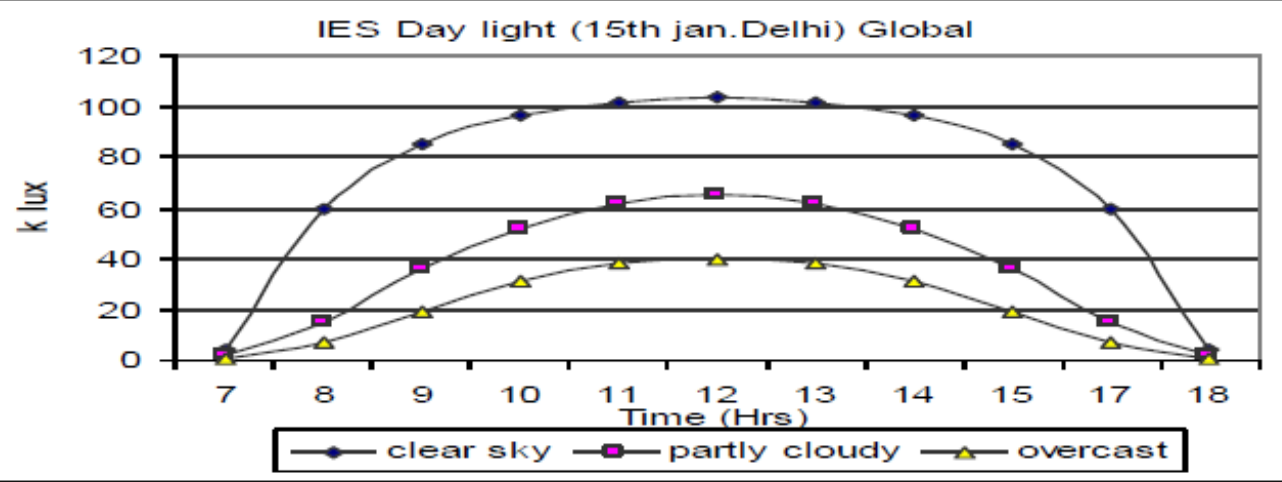

Figure 1. Global daylight intensity 15th Jan

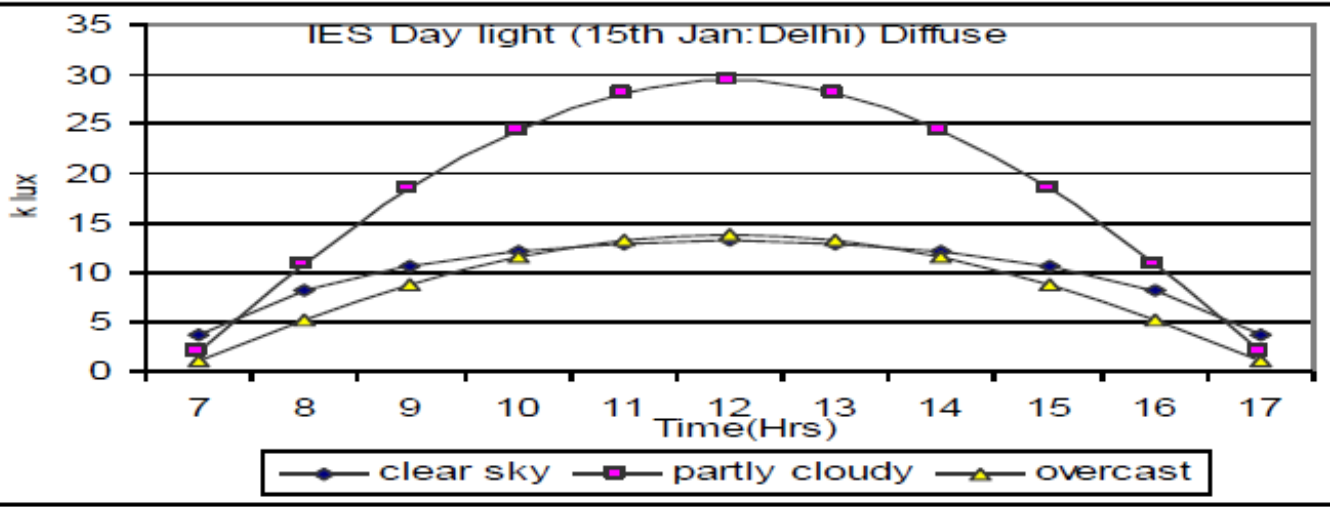

Figure 2. Diffuse daylight intensity 15 th Jan

IES Daylight (15th jan:Delhi) Beam

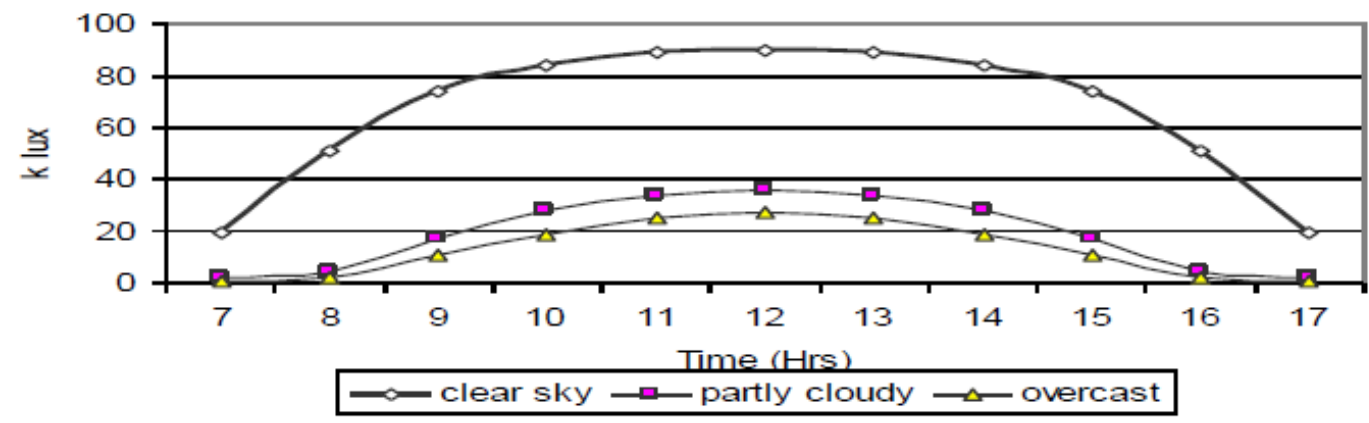

Figure 3. Direct daylight intensity 15 th Jan 
Fig: 4, Fig. 5 and Fig. 6 show computed values of daylight intensity of direct, diffuse and global for overcast, partly cloudy and clear sky conditions for $15^{\text {th }}$ June respectively. It is found that the least average daylight of 9.92 klux (say Approx. 10000 lux) is available for diffuse conditions for the period of January. As the least average daylight availability is the prime consideration for the design of daylight, the 9.92 klux is considered for the designing the window/openings.

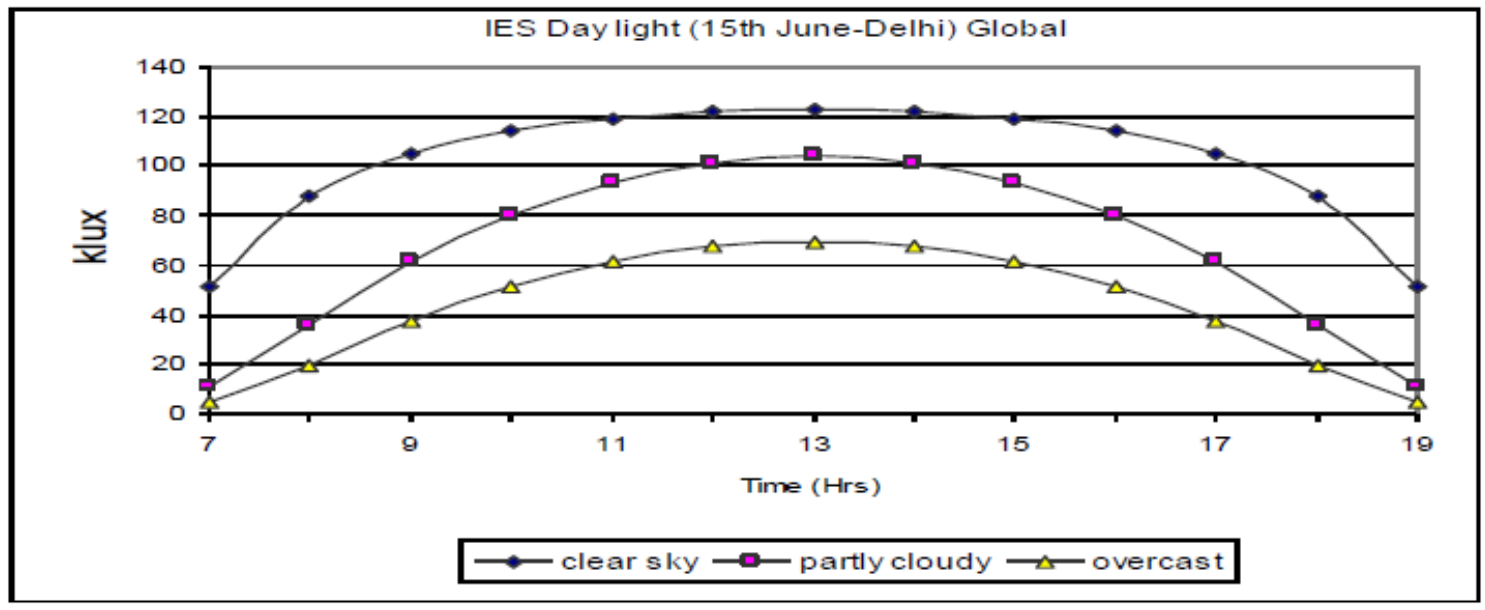

Figure 4. Global daylight intensity 15th June

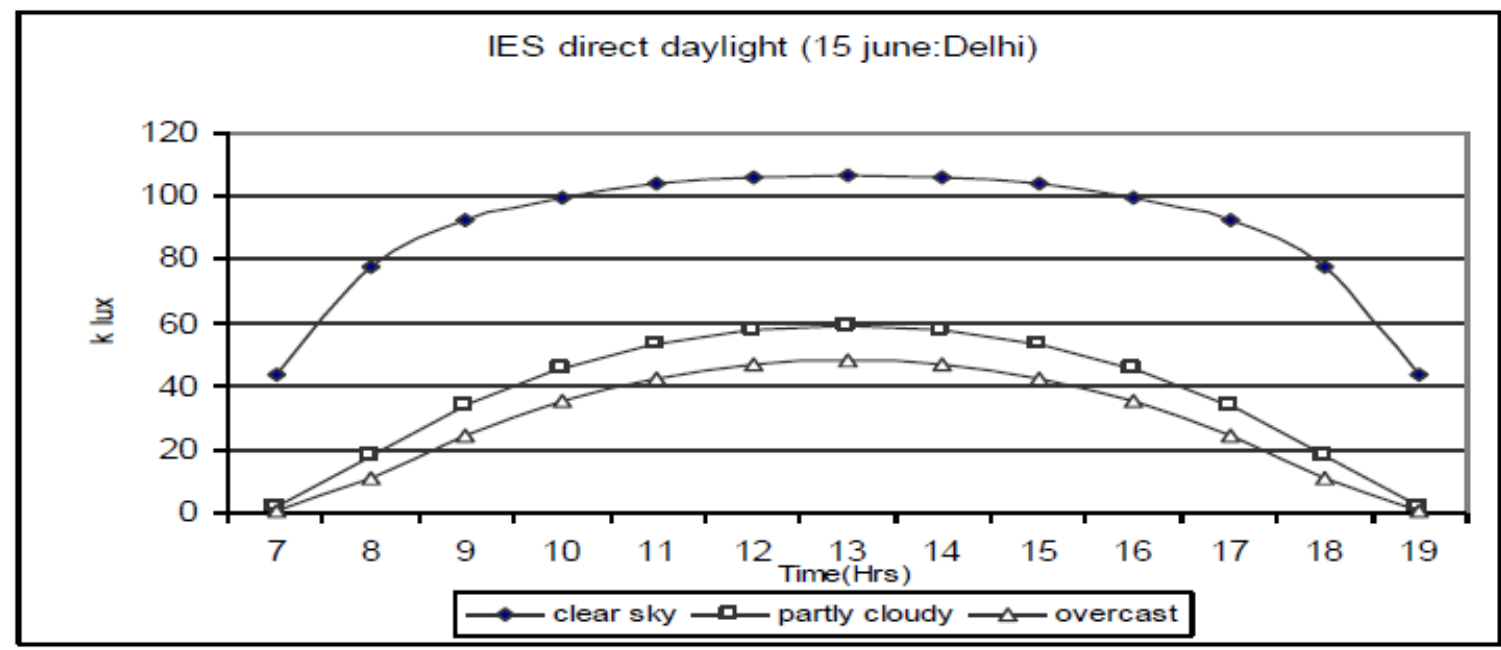

Figure 5. Beam daylight intensity 15th June

IES Diffuse Daylight(15th June-Delhi)

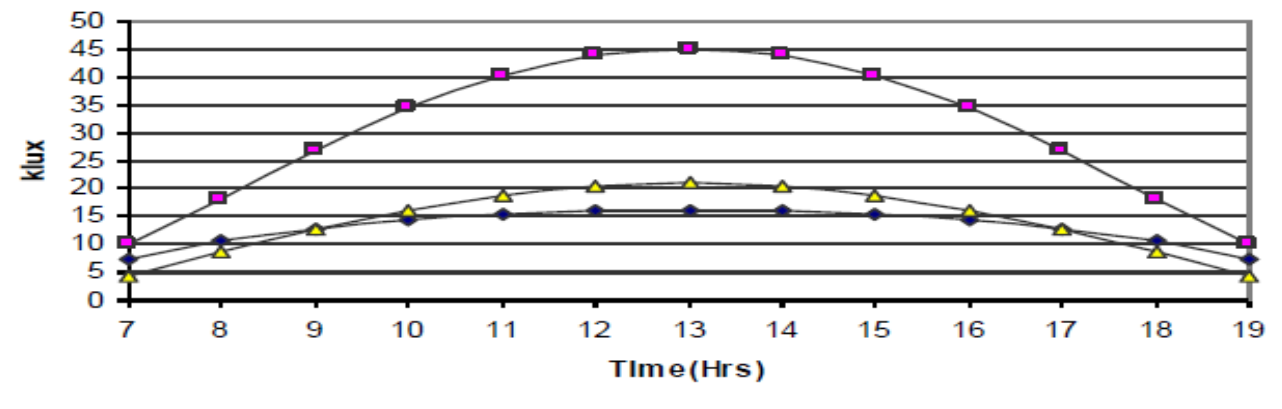

clear sky $\rightarrow$ partly cloudy $\sim \sim$ overcast

Figure 6. Diffuse daylight intensity for 15th June

For daylight design the diffuse daylight is the main parameter, hence the available diffuse daylight is computed by the IES day light model and compared to the practical results. 
Fig. 7 shows the comparative daylight intensity on January for Delhi. It is seen from the figure that the IES Daylight is having perfect agreement to the experimental measurements of diffuse sky for Delhi region. The same has been considered for design sky.

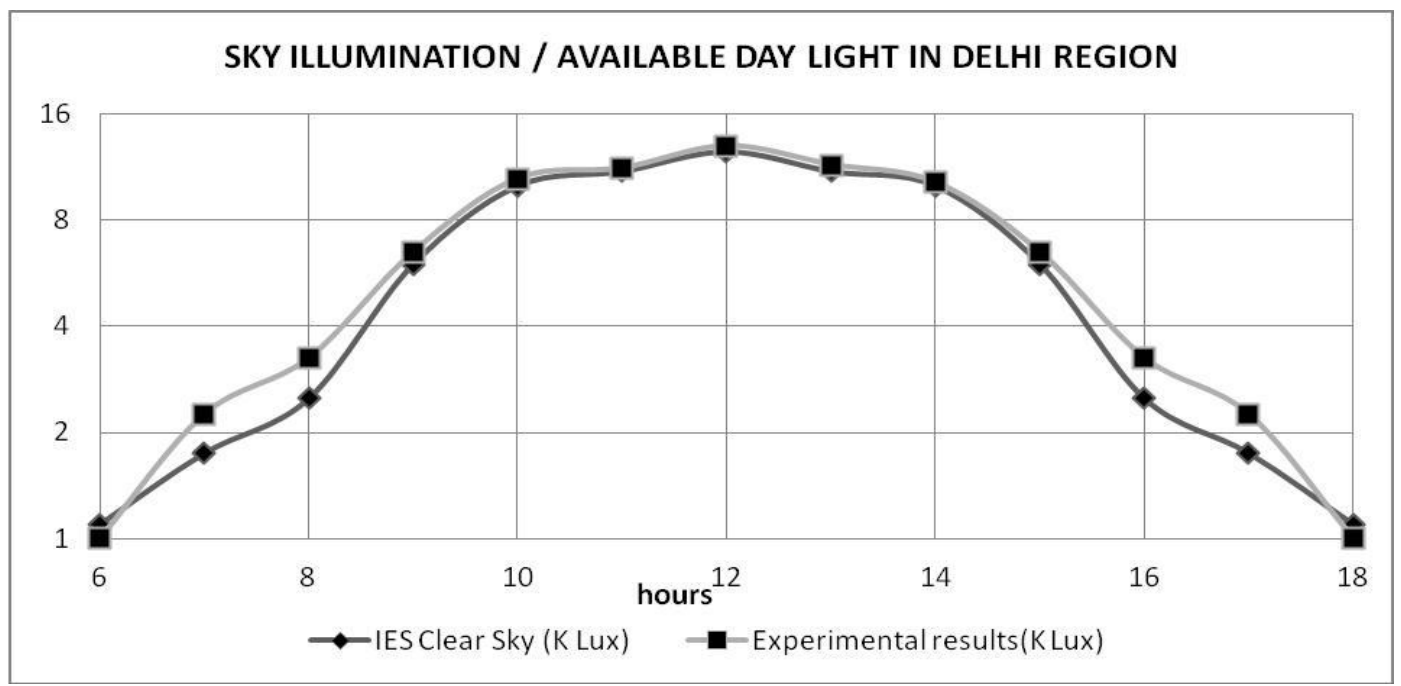

Figure 7. Comparison of diffuse daylight intensity with available experimental results.

The Bureau of Indian standard [18] has adopted clear design sky for day lighting corresponding to $15^{0}$ solar altitude and the design illumination has been considered as 8000lx. It is recommended for calculating of the sky component for the entire country. As per derived daylight for day lighting design is of 10000 lx within $20 \%$ of the design values adopted by NBC 2005. Accordingly, the daylight factor for different activities have been arrived with respect to the design sky of 10000 lux and shown along with the Daylight factors in Table 2

Table 2 Daylight factors for different activities:

\begin{tabular}{|c|c|c|}
\hline Location & Desired Lux & $\% \mathrm{DF}$ \\
\hline & \multicolumn{2}{|l|}{ DWELLINGS } \\
\hline Kitchen & 200 & 2.00 \\
\hline Living room & 50 & 0.5 \\
\hline Study/drawing room & 152 & 1.52 \\
\hline \multirow[t]{2}{*}{ Circulation } & 25 & 0.25 \\
\hline & \multicolumn{2}{|l|}{ SCHOOLS } \\
\hline Classroom & 152 & 1.52 \\
\hline Lecture theatre & 160 to 200 & 1.60 to 2.00 \\
\hline Study hall & 160 to 200 & 1.60 to 2.00 \\
\hline Laboratory & 152 to 304 & 1.52 to 3.04 \\
\hline \multicolumn{3}{|l|}{ OFFICES } \\
\hline General & 152 & 1.52 \\
\hline Drawing & 300 & 3.00 \\
\hline Enquiry & 50 to 152 & 0.51 \\
\hline & \multicolumn{2}{|l|}{ HOSPITALS } \\
\hline General ward & 100 & 1.00 \\
\hline \multirow[t]{2}{*}{ Pathological laboratory } & 200 to 300 & 2.00 to 3.00 \\
\hline & \multicolumn{2}{|l|}{ LIBRARIES } \\
\hline Stack room & 72 to 152 & 0.72 to 1.52 \\
\hline Reading room & 152 to 300 & 1.53 to 3.00 \\
\hline Counter area & 200 to 300 & 2.00 to 3.00 \\
\hline Catalogue room & 152 to 200 & 1.52 to 2.00 \\
\hline
\end{tabular}

\section{CONCLUSION}

The modified daylight factors to the context specific may help to determine the accurate daylight levels during summer and winter of Delhi region, India. These results facilitate architects, planners, engineers and lighting experts to work out an 
efficient system so as to conserve the illumination energy, appropriate desirable levels of lighting as per internal layout of different use specific buildings. Besides, there is a further scope to design the window/ opening sizes so as to draw daylight on vertical and horizontal surfaces of the functional spaces. The simulated results of IES model shown in conformity with the experimental results, so these results can be used in entire Delhi region to integrate the day lighting in the architectural design, so as to conserve the energy accurately with dimmer controls. In case of any variations due to the partly cloudy and cloudy conditions, the same thing can be controlled in conjunction with the dimmer controls of the artificial lighting to achieve adequate lighting levels in order to conserve the energy.

\section{REFERENCES}

[1] ASHRAE, ASHRAE hand book of fundamental, ISBN 1-883413-45-1,1997

[2] Bansal, N. K. "Emerging trends for energy efficiency in Buildings," International Journal of Renewable Energy Engineering, Vol .I,

a. No:3.,Dec'1999.

[3] (BIS), The Bureau of Indian Standards. 'Guidelines for day lighting '.IS 2440-1975., 2nd Rev.1989.

[4] Chandra,M. 'Luminous efficacy of solar radiation and evaluation of natural illumination'. Energy Convers. Mgmt vol.37, no.11, pp.1632-1634, 1996.

[5] Chauvel. P., 'Glare from windows: Current views of the problem,' Lighting research and technology, Vol.14. No.1, pp.31-46, 1982.

[6] (CIE) Commission International de L'Elairage, "Standardization of Luminance distribution on clear skies," CIE publication no.22,

[7] Didoné EL., Pereira FOR. 2011. Integrated computer simulation for considering daylight when assessing energy efficiency in buildings. Proc. of the 12thConference of International Building Performance Simulation Association, Sydney, Australia.,2011

[8] ECBC 2005, Energy Conservation Building Code, 2005

[9] Gillette, G., Pier Point, W., and Treado,S., "General Illuminance Model for Daylight Availability," Journal of the Illuminating Engineering Socity,pp.330 -340.,1984.

[10] Gupta.,V ‘ Energy and Habitat’ Wiley Eastern ltd.,India1984.

[11] IES Daylight Metrics Committee. 2012. IES Spatial Daylight Autonomy (sDA) and Annual Sunlight Exposure (ASE). Report LM-83-12.,2012. http://www.ies.org.,2012

[12] IES Lighting Handbook, Tenth Edition. New York, NY: Illuminating Engineering Society. 2010.

[13] LEED v4 BD+C: Schools - Daylight. Washington, DC: U.S. Green Building Council. Delos Living. 2013.

[14] LM-83-12, IES Spatial Daylight Autonomy (sDA) and Annual Sunlight Exposure (ASE). New York, NY: Illuminating Engineering Society. 2012.

[15] Lorenz,W., 'A glazing unit for solar control, day lighting and energy conservation'., Solar Energy.,70.,109.,2000.

[16] McCluney, R., 'Advance fenestration and day lighting systems'. Proceedings of international conference on Day lighting technologies for energy efficiency in buildings'. ottava, Canada.,10-13 may 1998.

[17] Mchugh,J.R 'MS thesis-Day lighting design via Monte Carlo' Colorado state university, Department of mechanical engineering., Fort Collins.,Colorado.1995.

[18] National Building Code - NBC 2005

[19] Perez,R.,Ineichen,P.,Seals,R. 'Modeling Daylight availability and Irradiance Components from Direct and Globle Irradiance', solar Energy,Vol.44,No.5,pp.271 to289. 1990.

[20] Reinhart, C.F., Mardaljevic J., Rogers Z. Dynamic daylight performance metrics for sustainable building design. Leukos, 3: 1-25.,2006.

[21] Shen H., Tzempelikos A. 2011. Day lighting and energy analysis of private offices with automated interior roller shades. Solar Energy, 86: 681704.,2011.

[22] TERI, Min. of non - conventional Energy Sources 'Energy-efficient buildings in India' TERI and MNEC, 2001.

[23] Tzempelikos A., Athienitis AK. 2007. The impact of shading design and control on building cooling and lighting demand. Solar Energy, 81: 369382.,2007.

[24] The WELL Building Standard., v1 with January 2017 addenda. New York, NY: Delos Living LLC. 2017. 